The effect of Povidone-iodine (PVI) irrigation on thyroid function test in children

M. Yafi, K.Tsao, K.Anderson, L. Putnam and K.Lally

UTHealth, The University of Texas Health Science Center at Houston

Michael.yafi@uth.tmc.edu

\title{
Background and aim:
}

Povidone-iodine (PVI) is an antiseptic solution with bactericidal properties commonly used in patients undergoing intra-abdominal surgery.

The aim of this study was to assess systemic absorption of total iodine by its effect on thyroid function test after PVI irrigation for perforated appendicitis surgery.

\section{Methods:}

Ten patients with perforated appendicitis got a thyroid function test (TSH and free T4) before and after surgery for perforated appendicitis. Each patient received a dilute $P V I$ solution $(1: 9)$ in a dose of $10 \mathrm{~mL} / \mathrm{kg}$, the irrigation was a one minute 12 time in the right lower quadrant as well of the pelvis after the appendix was removed by laparoscopic surgery

\section{Results:}

Nine of ten patients had normal thyroid function tests before and after the PVI irrigation. One patent with a strong family history of hypothyroidism was found to have a high TSH prior to the procedure and was excluded, subsequent testing confirmed the diagnosis of thyroiditis with hypothyroidism (positive Anti TPO) and was treated appropriately with Levothyroxine after surgery.

\section{Conclusions:}

A single use of intraoperative bowel irrigation with povidone-iodine may be performed with practically negligible risk of affecting the thyroid function. Screening for thyroid disease is not recommended prior to PVI irrigation unless it is a part of the standard medial approach when there is a strong family history and /or suggestive symptoms. Caution may be need with PVI is used with repeated procedures or when body surface area of the child is small.

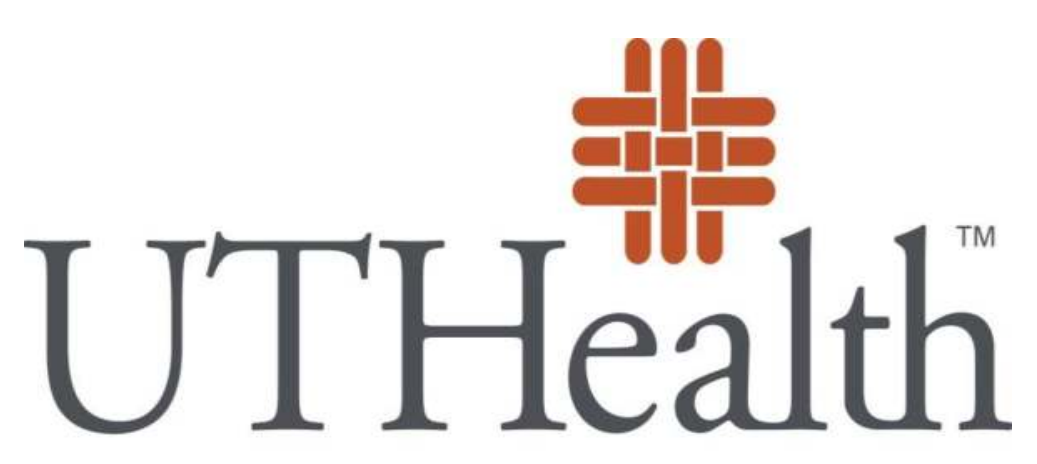

